\title{
SOBRE EL CANON DE BELLEZA PETRARQUISTA Y LA LUZ EN LA FILOSOFÍA NEOPLATÓNICA
}

\author{
Ginés Torres Salinas \\ Universidad de Granada
}

\section{RESUMEN}

El presente trabajo pretende estudiar, a partir de ejemplos de la poesía española del siglo XVI, cómo el canon de belleza petrarquista se relaciona con el papel de la luz en la filosofía neoplatónica. El cabello rubio, la piel blanca hasta la transparencia o la mirada luminosa no son simples tópicos, sino que encuentran en la época plena justificación, soporte filosófico, en la luminosa metafísica neoplatónica del amor.

Palabras clave: luz, neoplatonismo, canon de belleza petrarquista, poesía española del siglo XVI.

ON THE PETRARCHAN CANON OF BEAUTY IN 16TH CENTURY

SPANISH POETRY ACCORDING TO THE NEOPLATONIC PHILOSOPHY OF LIGHT

\section{Abstract}

This paper aims to study, from examples of 16th century Spanish poetry, how the Petrarchan canon of beauty is connected with the function of light in Neoplatonic philosophy. The blonde hair, the white skin to the transparency or the luminous glance are not simple topics, but they find at the time full justification, philosophical support, in the luminous Neoplatonic metaphysics of love.

KEYwORDs: light, neoplatonism, Petrarchan canon of beauty, 16th century Spanish poetry. 


\section{INTRODUCCIÓN}

El primer jalón de la imagen de la dama petrarquista en la literatura espanóla del Renacimiento lo encontramos en el conocidísimo soneto XxiII de Garcilaso ${ }^{1}$. En él, junto a las reminiscencias clásicas del «collige, virgo, rosas y el carpe diem» (Lapesa 1985: 154), ya detectadas por Fernando de Herrera en su comentario del soneto en las Anotaciones (2001: 422-423), aparece la prototípica imagen de la dama petrarquista, la cual, si bien encuentra espejo inmediato y concreto en un soneto de Tasso (Morros 2007: 116), remite al modelo que para el Renacimiento fija la Laura de Petrarca - de ahí que se hable de imagen de la dama petrarquista o de canon de belleza petrarquista, como de hecho haremos a lo largo de estas páginas-, manifestación a su vez de una amplísima tradición literaria que podría remontarse hasta Homero².

El soneto de Garcilaso es la más acabada cristalización de una imagen que ofrece una piel blanquísima, "de rosa y d'azucena»; un cabello rubio y brillante como el oro: «que'en la vena/ del oro s'escogió»; y unos ojos claros y llenos de luz: «vuestro mirar, ardiente, honesto, / con clara luz la tempestad serena». Con tal imagen, Garcilaso dota a la dama de un tipo de belleza que, a pesar de su amplio recorrido en la tradición clásica, «estuvo de moda durante los siglos XV y XVI. Recuérdense las rubias figuras de mujer creadas por Botticelli, Correggio y Tiziano; recuérdense también las verdes pupilas de Melibea y los claros y serenos ojos que cantó Cetina" (Arce 1969: 36) 3 . Esta imagen, que se convierte en algo más que una "moda», se extenderá a un amplio número de textos, no solo líricos, de la literatura renacentista y barroca, hasta constituir un canon estético tan densamente poblado en nuestras letras áureas que Adolphe Coster mostraba su perplejidad ante el hecho de que la imagen de Leonor de Gelves que Herrera ofrecía en sus versos fuera una «rareté hautement prisée sous le ciel andalou» (1908: 130).

Será el propósito de estas páginas demostrar cómo tal imagen, a pesar de llevar trazado ya un largo recorrido en tanto que tópico literario, adquiere en la poesía del siglo XVI un significado muy concreto que, lejos de constituir una serie de «metáforas fosilizadas de la descriptio puellae» (Navarro Durán 1994: XI), encuentra pleno sentido en la discusión filosófica sobre el amor y la metafísica del alma que se

${ }^{1}$ Utilizaremos la edición de la Obra poética y textos en prosa preparada por Bienvenido Morros para Crítica (2007). A ella referirán los poemas citados, cuyo número bastará para los sonetos, mientras que, en el caso de las églogas u otras composiciones largas, se añadirá entre paréntesis la referencia a número de los versos a los que se remite.

2 Aunque la propia Muñiz haya escrito que «escasean los estudios filológicos encaminados a reconstruir la morfología del topos a lo largo del tiempo» (2014: 152), ella misma ha paliado (2018) en buena medida el problema con su minuciosa puesta al día y reconstrucción del tópico. Aparte de este, ineludibles son, para la imagen renacentista de la dama, los trabajos de Pozzi (1976; 1979), Raimondi (1982: 163-187) y Quondam (1991: 291-328). En la literatura espańola, cfr., además, Manero Sorolla (1990; 1992; 2005) y, ahora, Trillini (2017). 193-199).

${ }^{3} C f r$., para un pequeño pero sustancioso recorrido iconográfico por el mismo, Eco (2004: 
impone con fuerza en Europa a través de ciertos tratados de amor herederos de la tradición de la filosofía neoplatónica liderada por Marsilio Ficino.

\section{LUZ Y AMOR EN EL NEOPLATONISMO RENACENTISTA}

Que el modelo de belleza petrarquista cuente con un amplio y caudaloso recorrido desde la tradición clásica y medieval no significa que tal canon haya sido siempre leído del mismo modo. Antes al contrario, los topoi no son entidades esenciales y ahistóricas, siempre iguales a sí mismas en el devenir del arte o las letras, sino que son leídos y reproducidos según las coordenadas ideológicas, culturales y literarias imperantes en el momento en que los artistas, los poetas en nuestro caso, componen sus textos. Aunque es bien conocida la conexión teórica entre el petrarquismo y el neoplatonismo, conviene siquiera plantear aquí las líneas básicas de su dimensión luminosa en relación con la imagen de la dama petrarquista ${ }^{4}$, pues el papel de la luz en la filosofía neoplatónica, central, por otro lado, en esta ${ }^{5}$, explica la aparición del canon luminoso del cabello dorado, la piel blanca casi cristalina y los ojos brillantes. Así lo demuestra la tratadística amorosa de raigambre neoplatónica, como el De amore, de Marsilio Ficino; El cortesano, de Castiglione; o los Diálogos de amor, de León Hebreo.

Podemos partir de una idea básica: el amor es deseo de belleza, en tanto que esta remite al Bien - «el amor es felicísimo porque es bello y bueno» (1986: 15) - y, por ende, a la divinidad. Así lo afirma Ficino en el De amore, en varias ocasiones: «Cuando decimos amor, entended deseo de belleza» (1986: 14); «El amor considera el disfrute de la belleza como su fin» (p. 15); «el amor hacia el hombre apetece esa belleza misma» (p. 16); «¿Por lo demás, ¿qué buscan estos cuando se aman mutuamente? Buscan la belleza, pues el amor es un deseo de disfrutar la belleza» (p. 18). La idea se extiende de Ficino a otros tratadistas. Castiglione, «qu'il a mieux compris et plus fidèlement suivi le système de Ficin» (Festugière 1941:

${ }^{4} C f r$. Lida, para quien conviene «no echarse en olvido que el alto papel del amor en el platonismo y en todos sus derivados facilitó el tránsito del aula de filosofía a la poesía amorosa, y en particular el tránsito del elogio de la amada como obra admirable de Dios al que la elogia por considerarla como creada por Dios "a su imagen y semejanza" - no en el sentido del Génesis, sino en el de la teoría de las ideas, como reflejo de la Suma Belleza, la Suma Luz» (1975: 253); o Manero Sorolla: «Los poetas más representativos del petrarquismo italiano y español en el Cuatrocientos, pero, especialmente, en el Quinientos, seguirán expresando a la amada a través de la luz, tanto más cuanto que las nuevas fórmulas y concepciones canonizadas por Bembo y, en general, la tratadística amorosa neoplatónica, tan íntimamente unida al desarrollo del petrarquismo en el Renacimiento, harán de las estética de la belleza en general, y de la particular de la dama, la apoteosis de la luminosidad de inmediato origen ficiniano" (1992: 68-69).

5 «No se apartaría mucho de la verdad quien afirmara rotundamente que todo el pensamiento de Ficino cabe entre estos dos temas populares: la luz o el amor» (Garin 2000: 236); «Es la metafórica de la luz, y del fuego, la que da la verdadera comprensión del pensamiento ficiniano» (De la Villa 1986: XxIII-XXIV). 
46), según Morreale el mejor transmisor del neoplatonismo en la Europa del xvi (1959: 149), habla de «la hermosura que nosotros agora tratamos, la cual es solamente aquella que aparece en los cuerpos, y en especial en los rostros humanos, y mueve aquel ardiente deseo que llamamos amor» (2009: 430). León Hebreo, en su particular «síntesis platónico-aristotélica» (Soria Olmedo 2002: 21) ${ }^{6}$, se acercaría a tal idea a través de la noción de la carencia y del deseo como movimiento: «Pero dejando de lado las ficciones y las opiniones de los demás, te diré que el padre común de todo amor es lo bello, y la madre común es el conocimiento de lo bello unido a la carencia de él» (2002: 278).

Este amor neoplatónico tendrá una doble naturaleza que Ficino representa con la imagen de las «dos Venus, a las que acompañarían dos amores [...] una de estas Venus es celeste, y la otra, vulgar» (1986: 38) ${ }^{7}$. La primera "es arrastrada por el amor innato a comprender la belleza de Dios», y la segunda, por su parte, es arrastrada, por su amor, «a crear la misma belleza en los cuerpos» (p. 39). El amor corporal, el humano, no será otra cosa, desde el punto de vista estricto del neoplatonismo, que un modo de acceder al verdadero amor, esto es, el de la divinidad, el de la Venus celeste. Lo ilustra a la perfección Castiglione cuando se ocupa de la pregunta que da pie al razonamiento amoroso del cuarto libro de El cortesano, si es adecuado y posible el amor en los ancianos. La respuesta es afirmativa: «Y más que, en viéndose declinar a la vejez, dexen de amar con este amor que agora decimos, y se retrayan, apartándose del deseo que la sensualidad trae, como del más baxo paso de aquella escalera por la cual se puede subir al verdadero amor» (2009: 433). De este modo, para el neoplatonismo, la belleza de los cuerpos será una suerte de escalón hacia el amor de las almas y la divinidad, no un fin en sí mismo, sino un medio para completar el acceso hacia la belleza inteligible ${ }^{8}$.

Otro de los elementos centrales de la filosofía amorosa neoplatónica es el de la noción de vínculo. Tras remitir a Orfeo para calificar al amor de «portador de las llaves de todo» (1986: 59), Ficino escribe que "con razón se puede llamar al amor nudo perpetuo y cópula del mundo, sostén inmóvil de sus partes y fundamento firme de toda la máquina [del mundo]» (p. 59). Todo lo cohesiona el amor, que es «mago» (p. 153), porque

toda la fuerza de la magia se basa en el amor. La obra de la magia es la atracción de una cosa por otra por una cierta afinidad natural. Las partes de este mundo, como miembros de un solo animal, dependiendo todos de un solo autor, se unen entre sí por su participación de una sola naturaleza (p. 154).

\footnotetext{
13-14).

${ }^{6}$ Cfr. Menéndez Pelayo (1974: 487-488), Soria Olmedo (1984: 73-76), Dagron (2006:

7 Para la imagen de las dos Venus, $c f r$. Saitta (1923: 243), Wind (1998: 130-149), Panofsky (2008: 201-202) y Castelli (1984: 57-58); para la misma imagen en la tradición hispánica, Soria Olmedo (1984: 134-137) y Vicente (2007).

${ }^{8}$ Cfr. Festugière (1943: 35), Margolin (1986: 599), Reyes Cano (2008: 47), Parker (1986: 63) y Serés (1996: 189).
} 
Como ha estudiado Culianu, el eros mágico del Renacimiento funciona a través del vinculum, de modo que

el mago, tanto puede ejercer su influencia sobre los objetos, los individuos y la sociedad humana, como invocar la presencia de los potentes seres invisibles, los demonios y los héroes [...]. Para poder actuar en este sentido, debe acumular el conocimiento de las redes y los cebos que tiende para alcanzar el efecto deseado. Esta operación se llama, según Giordano Bruno, «vincular» (vincire), y sus procedimientos reciben el nombre genérico de «vínculos» (vincula) (1999: 130).

El amor, así, queda dotado de un indudable carácter dinámico y unificador en tanto que «occupava, come nodo, un posto proprio in mezzo e acanto alle altre cose e le univa per la sua forza in una conessione viva» (Kristeller 1988: 113)9.

Esta noción de vínculo que adquiere el amor, su capacidad para servir de elemento cohesionador de todas las instancias de la realidad, explica la unión que el neoplatonismo establece entre la filosofía amorosa y el símbolo luminoso, y que justificará buena parte de las particularidades del canon de belleza femenino en los poemas del xvi. Son dos más los vínculos que se solapan al del amor en la filosofía neoplatónica. El primero de ellos es la luz, como el propio Ficino pone de manifiesto en el capítulo XI de su tratado De lumine:

No solo transfiere todas las virtudes de las estrellas a las siguientes, sino que lanza al Sol mismo y a las estrellas hacia las inferiores. Del mismo modo que nuestro espíritu conduce las fuerzas del alma y el alma misma hacia los humores y los miembros, $\mathrm{y}$, así como también, el espíritu es en nosotros nudo del alma y del cuerpo, del mismo modo la luz es vínculo del universo (2013: 2466-2469).

La concepción de la luz como vínculo del universo le reconoce la misma fuerza de atracción, de integración de todos los elementos de este, siendo así, igual que el amor, «una luz que todo lo abarca y en lo que todo vive» (Díaz-Urmeneta 2014: 97).

A este solapamiento se le debe unir otro plano igualmente fundamental para entender la filosofía neoplatónica del amor, como es el del alma. También esta, en el sistema neoplatónico, es entendida como un vínculo, merced a su papel de mediadora entre lo angelical y lo animal. Así la califican Pico della Mirandola, cuando habla de ella en el Discurso de la dignidad del hombre como de «vínculo unificador, o mejor dicho, himno nupcial del mundo» (2000: 99); o el propio Marsilio Ficino en la Theologia Platonica al estimar que es «medio universal, cadena del mundo, expresión del todo, nudo y vínculo del universo» el auténtico nudo de todo lo que hay en el universo» (2001: 242-243) ${ }^{10}$. Tal papel

9 Para la cuestión del amor como fuerza de atracción, $c f r$. Saitta (1923: 248-249), Rodríguez (1990: 187), Foucault (1972: 32), Serés (1996: 171).

${ }^{10}$ La traducción es nuestra: «Universorum medium, mundi series, vultus omnium nodusque et copula mundi». 
de vínculo tendrá una serie de consecuencias que nos interesa destacar en nuestro razonamiento. En primer lugar, la identificación del alma con la luz. Efectivamente, el alma será luminosa y así lo manifestará el neoplatonismo. De nuevo Ficino es quien traza la identificación, en varios lugares de la Theologia Platonica: «La luz no es otra cosa que un alma visible [...] y el alma es una luz invisible» (2002: 346-347) ${ }^{11}$; «elimina, te pido, la materia de la luz y pon aparte lo que resta: de repente, has obtenido el alma, esto es, luz incorpórea, colmada de todas las formas, pero mutable» (2003: 20-21) ${ }^{12}$; «recuerda que eres espíritu incorporal, luminoso por naturaleza, bueno e inmortal, capaz de la eterna verdad y estabilidad del inmenso bien" (1952: 949) ${ }^{13}$.

Queda el último paso, también brindado por Ficino, que cierra el círculo abierto cuando señalamos que el amor era deseo de belleza. Hasta en dos ocasiones pregunta a su interlocutor en el De amore: «¿Es que crees que la belleza es otra cosa que luz?» (1986: 51, 71). Aseveración que comparte León Hebreo: «También la luz es bellísima» (2002: 285). Si, como afirma Ficino, «la belleza es un resplandor que atrae a sí el espíritu humano» (1986: 47), esta adquiere también la posibilidad de solaparse a la noción de vínculo, central, como se viene explicando, para la concepción neoplatónica del amor ${ }^{14}$. Si el amor es deseo de belleza, si la belleza es luminosa, si ambas son vínculos del mundo y si, a la vez, el alma es también vínculo luminoso, el amor neoplatónico será un deseo atractivo de la luz de alma, cerrándose así un círculo en el cual Ficino «traccia una teoria dell'amore, che è una vera e propria dialettica dell spirito" (1923: 220). El amor sería así un impulso a partir del cual «l'Amant s'attache donc à l'âme de l'amie, et qu'il en aime la beauté» (Festugière, 1941: 34), en busca de lo que Serés estudió como la "transformación de los amantes» (1986), en palabras de Chastel, «el amor platónico entre los sexos o la unión espiritual de las almas» (1982: 293).

Poco a poco se puede ir comprendiendo el particular asidero que el Renacimiento encontrará en el modelo petrarquista de belleza, en tanto que su luminosidad encaja a la perfección con los parámetros establecidos por la doctrina neoplatónica. La belleza, que desencadena el proceso amoroso, tiene más de incorpóreo que de proporción corporal ${ }^{15}$, por lo que «está más allá de la captación normal de los sentidos, [y que] puede solamente expresarse en términos de luz, ya que esta es idéntica al espíritu» (Chastel 1982: 286). Tal naturaleza tiene una consecuencia que

${ }^{11}$ La traducción es nuestra: «lumen nihil aliud est nisi visibilis anima, [...] anima vero lux invisibilis».

${ }^{12}$ La traducción es nuestra: «Subtrahe, quaeso, materiam lumini, relinque caetera, subito habes animam, incorporeum videlicet lumen, omniforme, mutabile».

${ }^{13}$ La traducción es nuestra: «memento te esse spiritum incorporeum, lucidum natura, bonumque immortalem aeternae veritatis ac stabilitatis immensique boni capacem».

14 «¿Qué es el vinculum? Es, evidentemente, la belleza en su sentido más amplio. Pero esta belleza que vincula no consiste en una cierta proporción de los miembros. Se trata de una "razón incorpórea" que difiere según las disposiciones de cada uno [y que] se explica por una correspondencia secreta entre el enamorado y el objeto de su amor» (Culianu 1999: 141).

15 Cfr. Ossola (1971), Kristeller (1988: 285-286), De la Villa Ardura (1986: xxix). 
enlaza directamente con la imagen renacentista de la dama: «La belleza de los cuerpos es luz, y la belleza del espíritu es luz» (1986: 182). Insistirá Castiglione en tal idea cuando aluda a «la hermosura del alma, la cual, como participante de aquella hermosura divina, hace resplandeciente y hermoso todo lo que toca, especialmente si aquel cuerpo donde ella mora no es de tan baxa materia que ella no pueda imprimille su calidad» (2009: 437-438). León Hebreo afirmará que «universalmente, la luz es forma en todo el mundo inferior, forma que quita de la materia informe la fealdad de la oscuridad, por lo cual hace más bellos los cuerpos que más participan de ella» (2002: 286). De este modo, en la tratadística neoplatónica del amor asistimos a una "cresciente spiritualizzazione del corpo" (1923: 254), en la que el cuerpo «será instrumento del alma, su medio de inserción en el mundo sensible [...] el extremo adelantado del esplendor divino en la naturaleza» (Chastel 1982: 290), de modo que «c'est en effet parce que son âme est belle que le corps de l'aimée est beau: et c'est à la beauté de son âme que doit nous conduire l'amour provoqué en nous par son beau corps» (Festugière 1941: 35).

$\mathrm{Si}$, en definitiva, "c'est la beauté de l'âme qui transparait à travers le corps» (Margolin 1986: 594), y esta belleza es luminosa -como lo es el alma-, no será de extrañar - a pesar de que no se haya estudiado la relación del tópico con la belleza inmaterial neoplatónica (Muñiz 2018: 100) - que, a la hora de establecer un canon de belleza femenino, el Renacimiento atienda a una figura de la dama luminosa en extremo. Cierto que con una larga tradición literaria a su espalda, pero es en ese momento cuando conoce su mayor y más terminado desarrollo, pues lejos de ser un conjunto de metáforas fosilizadas, ofrece una serie de posibilidades, de lectura de cada uno de sus elementos, que encajan perfectamente con los parámetros marcados por la filosofía neoplatónica del amor.

\section{LUZ Y NEOPLATONISMO \\ EN EL CANON PETRARQUISTA DE BELLEZA}

\subsection{El cabello}

Regresando a Garcilaso, si recordamos ahora el soneto xxiII o la descripción de Elisa en la primera égloga - «Los cabellos que vían / con gran desprecio al oro / como a menor tesoro" (vv. 273-275) - el pelo de la dama, de tan rubio, era de oro. En el soneto, cada cabello se había escogido en «la vena/del oro», esto es, en la fuente más pura del mineral que se encuentra en la naturaleza; mientras que en la primera égloga, el cabello de la dama, frente a frente con el oro, mira a este «con gran desprecio», no lo entiende más que como «menor tesoro». No es el único caso de una imagen muy extendida. Por poner algunos otros ejemplos representativos, Fernando de Herrera hablará en la canción Iv del segundo libro de los Versos (2006: 703-707) de «Las hebras esparzidas por el cuello, / cual oros en hilo vuelto» (vv. 49-50); o en el soneto IIX del primer libro de esos mismos Versos de cómo 
El oro, qu'al Gange indo en su ancha vena

luziente orna, i en hebras dilatado,

con luengo cerco i terso, ensortijado,

gentil corona en blanca frente ordena.

Francisco de Aldana, por su parte, se referirá en su poema vi, Pues tan piadosa luz de estrella amiga (1997: 138-145), a "ese oro sutil, nuevo y luciente, / que por mano de Amor se ordena y mueve» (vv. 169-170); así como, en el poema XxiII (pp. 251-274), habla de "Céfiro, entregado en la madeja/del húmido, ondeado y sotil oro" (vv. 333-334). Incluso, en las "Octavas a lo pastoral hechas recitar en unos desposorios de un hermano suyo» (pp. 209-218), el carácter jocoso de la composición abre un hueco al canon dorado del cabello:

Bésote, peine mío, mil y mil vueltas

y otro millón, pues has las hebras de oro,

que entre blanco marfil volaban sueltas,

tocado de mi bien y mi tesoro (vv. 97-100).

¿De dónde procede tal profusión de oro? En una primera instancia, la comparación con el oro se justifica en el color del cabello de la dama, semejante al del metal cuanto más rubia sea aquella. Sin embargo, el estudio de la comparación desde la perspectiva neoplatónica que venimos exponiendo en estas páginas aporta interesantes matices.

No es casual que el cabello de la dama sea de oro. O no se interpreta en su profundidad solo por el color del metal. Pensemos, para ilustrarlo, en unos versos del poema XxxiII de Francisco de Aldana (1997: 251-274), que se ocupa, «largamente, y con ejemplos ovidianos, de los efectos universales del amor erótico" (Rivers 1957: XVI). Nos interesa el momento en que el poeta se refiere a los dos tipos de flecha que Cupido lanza a los amantes. Unas serían las que acaban en «El casquillo emplomado, que desvía/ las hogueras de amor» (vv. 457-458) y otras las de oro, sobre las que se extenderá Aldana. Pese a que la imagen procede de la tradición clásica y de la trovadoresca ${ }^{16}$, Aldana la desarrolla, en lo que se refiere al oro, desde el espíritu del neoplatonismo renacentista. Tras remitir a los dos tipos de flecha, como se ha dicho, Aldana se detiene en el carácter del oro:

Dicen también que el oro al hombre inclina

a amar, y es por el Sol, con luz serena,

en los veneros de oro predomina,

do engendra la estimada y rubia vena;

y más de que a la complexión sanguina,

sujeta estando al Sol, Cupido ordena

herir con oro, por mostrar que luego

arde el sanguino en amoroso fuego (vv. 465-472).

16 Cfr. Dronke (1978: 108), Manero Sorolla (1990: 112), Ferraté (1982: 219-220). 
La naturaleza del oro, apunta Ferraté, se ve determinada por «las influencias celestes que, según los mismos astrólogos y los alquimistas, se ejercen de modo particular sobre los distintos metales» (1982: 219). En este caso, será el Sol quien se la otorgue, astro que, en palabras del poeta, «en los veneros de oro predomina». La acción del Sol sobre el mineral se concreta en su «luz serena», a través de la cual lo dota de su particular naturaleza. Una naturaleza que el propio poeta especifica y que interesa recalcar aquí: «el oro al hombre inclina/ a amar». En la imagen del oro se condensan amor y luz, vínculos ambos, ya lo sabemos, del universo, íntimamente relacionados entre sí para la doctrina neoplatónica. Si la luz es sello y manifestación del amor, el oro, metal de luz por excelencia, será aquel elemento de la naturaleza donde con más fuerza se manifieste, en forma de resplandor, la capacidad de atracción, la fuerza magnética de la belleza de la dama, de su alma luminosa. Como bien explica Muñiz, «non era però quello di Garcilaso un petrarchismo di superficie, bensì reinterpretato alla luce della propria vena neoplatonica ed elegiaca» (2018: 157). Aseveración que podemos extender a buena parte de los poetas españoles del XVI. Así lo confirma Aldana poco más adelante:

Después amor, cual de su tronco rama,

del amado metal su ser produce,

cuya vital cesando alta influencia

luego se muere amor de vil dolencia (vv. 477-480).

El cabello rubio de la dama petrarquista, oro puro, es una irresistible invitación al amor para el poeta, un carcaj de flechas de oro dirigidas al pecho del poeta.

Así pues, no habrá ninguna ocasión en la poesía de Garcilaso en que el cabello femenino no aparezca bajo el signo del oro. En la elegía I, cuando sus hermanas y su madre lloran la muerte de don Bernaldino de Toledo, la caracterización que de ellas hace el toledano sigue el patrón luminoso, pues a través de ella se muestra la dignidad de su alma: «a todas las contemplo desparciendo/ de su cabello luengo el fino oro, / al cual ultraje y daño están haciendo» (vv. 139-141). También las ninfas responden a tal canon de belleza. Si «estos Dioses [menores] interpretan con su canto el alma de la Naturaleza» (López Estrada 1974: 77), tales criaturas elementales, «neto ser de la naturaleza» (Alonso 1987: 72), son tratadas por Garcilaso como una suerte de deidades, cercanas a lo espiritual, lo que supone que no se alejen un ápice de la representación luminosa petrarquista. En el soneto XIII, al narrar la transformación de Dafne en laurel, Garcilaso escribirá que «en verdes hojas vi que se tornaban / los cabellos qu'el oro escurecían", del mismo modo que en la tercera égloga, de nuevo describiendo a Dafne, leeremos que «los cabellos que vencer solían / al oro fino, en hojas se tornaban» (vv. 163-164). En la segunda égloga, cuando Albanio las interpela para que atiendan a sus quejas amorosas, pide que "alce una de vosotras, blancas deas, / del agua su cabeza rubia un poco» (vv. 611-612). Esa cabeza rubia se repite en el soneto XI, en el que Garcilaso les ruega que dejen «un rato la labor, alzando / vuestras rubias cabezas a mirarme». En la tercera égloga, cuando una ninfa decide sacar la cabeza del agua, es descrita en tales términos: 
Peinando sus cabellos d'oro fino, una ninfa del agua do moraba

la cabeza sacó, y el prado ameno

vido de flores y de sombras lleno (vv. 69-72).

Sin salir de esta tercera égloga, las dríades son así rogadas por parte del poeta:

¡Oh dríadas, d’amor hermoso nido

dulces y graciosísimas doncellas

que a la tarde salís de lo escondido, con los cabellos rubios que las bellas

espaldas dejan d'oro cubijadas! (vv. 623-627).

Esta naturaleza del oro como manifestación física del vínculo amoroso se halla detrás de otra de las imágenes centrales de la caracterización de la dama renacentista en lo que se refiere al cabello. En la canción IV, Garcilaso explica así el inicio de sus penas de amor: «De los cabellos de oro fue tejida/la red que fabricó mi sentimiento» (vv. 101-102). No es el único. Herrera, en un soneto (2006: 265), confesará que "Destas doradas hebras fue texida/la red en que fui preso y enlazado"; mientras que en la séptima elegía de Algunas obras (2006: 459-465) es minucioso hasta el extremo: «Un sutil hilo pudo d'un cabello/más bello que la luz del Sol dorado, / traerme preso sin jamás rompello» (vv. 22-24).

La imagen, de filiación petrarquesca ${ }^{17}$, encuentra también legitimación en la filosofía neoplatónica. El quinto capítulo del De amore lleva por título "Cuán fácil somos envueltos por el amor en sus redes» (1986: 205), y en él Ficino expone que «caen más fácilmente en las redes [del amor] los que han nacido cuando Venus estaba en Leo, o cuando la Luna estaba aspectada por Venus» (1986: 215). Más allá de los aspectos astrológicos, nos interesa recalcar que la noción de red trasciende lo inmediato de la imagen para incrustarse en el engranaje de la filosofía amorosa renacentista. Así lo detalla Culianu:

El término ficiniano rete («red») no hace más que retomar otros vocablos acreditados, como illex, illecebra o esca, que significan casi lo mismo: «cebo». Al igual que un cazador, el enamorado y el mago -el mismo enamorado de la naturaleza, de Diana, diría Giordano Bruno- tienden sus redes, instalan sus cebos y sus seńuelos fantásticos para hacerse con una caza muy preciada (1999: 130).

El cabello de la dama es «la red maravillosa [que] ha despertado sus sentidos y su deseo" (Arce 1969: 35). Una red cuya efectividad atractiva depende en buena parte del material del que está hecha: el oro, cuya luz pura es un cebo inelu-

${ }^{17}$ Lapesa (1985: 75), Morros (2007: 87), García de la Concha (1986: 101-102) refieren la ballata LIX (Petrarca, 2006: 284); Lida (1975: 68, n. $\left.{ }^{\circ} 21\right)$ remite a los sonetos CXCVI, CXCVII y CXCviII; Manero Sorolla (1990: 156) lo hace al soneto CLXXXI. 
dible, un anzuelo, como vimos que escribía Ficino, que la belleza última de la dama tiende al alma del poeta.

Desde ese punto de vista se entiende la lectura que hace del canon Fernando de Herrera, quien para Rosa Lida «es por excelencia el platónico de la poesía española» (1975: 272). Se trata de una lectura en buena medida hiperbólica en lo tocante a la luminosidad del canon de belleza petrarquista. Podemos comprobarlo con varios ejemplos. La tercera canción de Algunas obras (2006: 433-436) habla de «el cabello sutil, crespo y dorado, / que, cuál de las estrellas, / por el aire volaron sus centellas» (vv. 76-78). En unas «Estançias» (2006: 288-289), les dice que "hebras del oro puro soys hermosas, y no doradas hebras del cabello» (vv. 31-32). En la cuarta canción del libro segundo de los Versos (2006: 703-707), Herrera describe el cabello de la dama como «Las hebras esparzidas por el cuello, / cual oro en hilos vuelto, i derramado» (vv. 49-50). El poeta sevillano se detiene no en el conjunto del cabello en general, sino en una multiplicación de hebras que analiza con minuciosidad microscópica, recuperando la imagen de la red analizada más arriba, cuando explica que, en tal profusión de hebras:

en unas haze Amor el yugo, i tiene

en otras fabricada

la red en que mi amado error sostiene,

presa de ricas piedras i esmaltada (vv. 59-62).

Una red que reaparece, plena de luminosidad, en el soneto Lxxxix del libro I de los Versos (2006: 600-601), dedicado enteramente al cabello de la dama. En un primer momento lo identifica con el ámbar: «Bel lo cerco i ondoso qu’, enlazado / en sutil vuelta i varia d'ambar pura, / tenéis mi preso cuello». Mientras que más adelante recurre al oro para ocuparse de la luminosidad del cabello, descrito con detalle y majestad: «no avrá en el suelo nuestro ni en el cielo / hebras luzientes d'oro terso tales, / ni d'amor tan hermosa red i llama».

Desarrolla Herrera una imagen del cabello absolutamente luminosa, en que el oro se asocia al fuego. Lo podemos comprobar en el soneto Lxxxix del libro primero de los versos, donde describe así el pelo de doña Leonor de Milán:

Trenças, qu'en la serena i limpia frente,

d'anillos d'oro crespo coronadas,

formáis luzientes vueltas i lazadas

donde'l mayor vulcano espira ardiente.

La canción $\mathrm{v}$ del mismo libro (2006: 609-612) ahonda en esta dirección, recurriendo de nuevo a la imagen de la red:

No son más rutilantes y encendidos, cuando salen más roxos en el día, los claros rayos de Titán luziente, que son, de la enemiga dulce mía, los hilos, o enlazados o esparzidos, 
con qu'enriquece Amor la blanca frente,

donde tiene presente,

de fuerte red i estrecha,

noble cadena hecha

al alma, que procura ser vencida (vv. 15-25).

La representación luminosa del cabello hace a Herrera saturar la descripción del cabello en una conjunción entre el oro y las piedras preciosas que adornan la frente de la dama:

Hermosos nudos, crespas trenças de oro en coronas luzientes sustentadas, que enriquecéys la blanca y roxa frente llena de puras perlas y lazadas, del propio, rico y celestial tesoro odores esparziendo de Oriente (vv. 27-32).

Incluso, en alguna ocasión, el cabello de la dama brillará tanto que será el oro el que tome del cabello de la dama su propia luz, dando lugar a una imaginería competitiva $^{18}$-que se repetirá en algunos de los demás elementos del canon-como es el caso del soneto XXXIII de Algunas obras (2006: 390), donde Herrera canta a las «Ardientes hebras, d s'ilustra el oro».

\subsection{LA BLANCURA DE LA PIEL}

Tanto como el dorado cabello resplandecerán el «blanco pecho» de Elisa en la primera égloga; «el cuello de marfil», la «blanca mano» de Camila en la segunda (vv. 21, 114); o el «blanco pie» no solo de la propia Camila (v. 858), sino también, en la tercera égloga, de las ninfas que salen del agua (v. 95), de Euridice justo cuando recibe la picadura de la serpiente (v. 130) o de la hermosa Dafne escapando de Apolo (v. 154). Fernando de Herrera ampliará el espectro cromático del blanco en sus poemas, ahondando en la dirección que encontramos en Garcilaso. Junto a la luz del cabello encontramos la de la piel. Así, la cuarta canción del libro segundo de los Versos, donde hallamos dos veces la combinación: cuando se refiere a «las trenças qu'aura mueve/por el marmóreo cuello que la nieve/ pura vence'n blancura» (vv. 8-10); y, más adelante, al ocuparse de la imagen de

Las hebras esparzidas por el cuello, cual oro en hilos vuelto, i derramado sobre'l terso marfil qu'el manso viento toca ledo i contento (vv. 49-52).

${ }^{18}$ Cfr. Reichenberger (1962). 
Una canción en metro italiano (2006: 292-296) extiende la caracterización a otras partes del cuerpo menos canónicas. La mano es resplandeciente, hecha de perlas traídas de India: «Rosada, tierna y bien compuesta mano, / de las perlas de Idaspes reluciente, / llena de mil vitorias con trofeo» (vv. 66-68); del mismo modo, el pie vence en su blanco a la nieve: «puras plantas, en quien perder consiente/la nieue el color vivo» (vv. 69-70). Aldana, por su parte, hablará en las octavas que versan sobre "Medoro y Angélica» (1997: 493-497) de la blancura del muslo de la protagonista, al escribir sobre "el muslo cual aborio limpio y puro» (v. 52) ${ }^{19}$; o de la ninfa Europa, quien en el ya aludido poema XxxıII nos ofrece «la pierna, que el marfil precioso muestra» (v. 308).

Es cierto que en un primer momento, el color blanco se puede asociar a la pureza $^{20}$, presente, junto al rojo sensual de la rosa, en la azucena del soneto xxiII. Fernando de Herrera así lo estima cuando comenta el verso 231 de la primera égloga, en referencia al ruiseñor: «porque el color blanco es puríssimo i el más perfeto de los colores: i por traslación al ánimo, se toma por sincero, i assí, blanca sinifica simple, senzilla, pura i piadosa» (2001: 719).

Sin embargo, la cuestión no se queda ahí. El propio Herrera nos pone sobre la pista luminosa que venimos manejando cuando se ocupa de la Luna en el verso 275 de la tercera égloga: «Los platónicos llaman blanca a la Luna porque haze blanca la noche con la blancura de su luz, i el color blanco es puríssimo" (p. 973). El poeta sevillano abre una interesante posibilidad con la filiación platónica de la imagen que relaciona el blanco con la luz. Desde esa perspectiva podemos acercarnos al papel que el neoplatonismo renacentista concederá a la blancura de la piel.

Partamos para ello de una expresión que usan tanto el propio Garcilaso, justo antes de la descripción de Elisa: « $¡ O$ Oh tela delicada, / antes de tiempo dada, / a los agudos filos de la muerte!» (vv. 260-261), como Herrera en la canción que se ha citado anteriormente, este incluso asociándolo al canon petrarquista de belleza: «Hermoso, blanco pecho, enhiesto cuello, / limpio marfil de açerbas pomas bellas / que dulcemente muestra el sutil velo» (vv. 79-81). Blecua señala el significado preciso de tela en estos versos: "en sentido de cuerpo humano que encubre el alma» (1955: 32), ya que "Garcilaso, como todos los hombres del siglo XVI, sabe que el cuerpo es la tela, velo mortal que encubre y contiene el alma y que impide el goce y la inteligencia de la belleza eterna» (Arce 1969: 78). En efecto, para el neoplatonismo renacentista, el cuerpo es un velo que establece una particular relación de ocultación y transparencia con el alma, esto es, con la luz con que esta resplandece. De tal relación se ha ocupado Chastel, quien escribe que

mais, revenant toujours volontiers sur le fait que le corps est parfaitement apte à traduire toutes les émotions de l'âme, il désigne, en particulier, les points d'ex-

$19 C f$ r. del propio Aldana, ciertos versos de la «Fábula de Faetonte» (1997: 148-187): «de precioso aborio/ que a la perla oriental vence en blancura» (vv. 427-428).

${ }_{20}$ Cfr. Manero Sorolla (1990: 289-295) para Garcilaso; Macrì (1972: 140-142) y Garrote Pérez (1997: 163) para Herrera. 
pression les plus attachants, ceux qui laissent transparaître la suavité et la pureté naturalles de l'âme, c'est-à-dire la région des yeux, qui communiquent la lumière intérieure et de la bouche qui s'incurve en sourire (1996: 104).

Esto es, "c'est la beauté de l'âme qui transparait à travers le corps» (Margolin 1986: 594). Nos hallamos así ante una relación cuerpo/alma en que no se da "la mezcla sustancial de espíritu y materia, sino, una vez más, los dos estratos paralelos (el espíritu y la carne)» (Rodríguez 1990: 293). Ambos se relacionan según una "manifestation extérieure» (Matton 1981: 37), que el neoplatonismo elabora a partir del «elemento determinante de la estructura productiva del platonismo poético» (Rodríguez 1990: 87): la "Extracción de la Idea oculta en la Materia» o «intento de materializar la «idea desnuda» (p. 151), según la cual «la verdad ha de ser desnuda [...] hay que quitarle toda su materia superflua para que aparezca resplandeciente en sí misma, para que se revele a los ojos humanos en toda su pureza estricta» (p. 153). Si, según explica Bachelard, «la sustancia tiene un interior, se ha de tratar de excavarla. Esta operación se denomina 'la extracción o la excentricidad del alma'» (1974: 120), y, si según esta lógica neoplatónica «un alma bella lo es por su capacidad de expresión» (Rodríguez 1990: 95), el alma tratará de expresarse a través del cuerpo lo más posible, esto es, tratará de brillar con su luz todo lo que permita este velo que le opaca, que le impide expresarse. Así se entienden pasajes como este de El Cortesano:

ha de considerar primero que el cuerpo donde aquella hermosura resplandece no es la fuente de donde ella nace, sino que la hermosura, por ser una cosa sin cuerpo y, como hemos dicho, un rayo divino, pierde mucho de su valor hallándose envuelta y caída en aquel sujeto vil y corrutible, y que tanto más es perfeta cuando menos dél participa, y si dél se aparta del todo, es perfetísima (Castiglione 2009: 441).

O la síntesis, en hermosa imagen, de fray Luis en La perfecta casada:

Porque así como la luz encerrada en lanterna la esclarece y traspasa, y se descubre por ella, así el alma clara y con virtud resplandeciente por razón de la mucha hermandad que tiene con su cuerpo, y por estar íntimamente unida con él, le esclarece a él, y le figura y compone tanto cuanto es posible de su misma composición y figura (1987: 168).

La piel blanca de las damas petrarquistas supone así una intensa expresión de la luz de sus almas, de ahí que Manero Sorolla hable de las «relaciones metafóricas [que] por su carácter abstracto y etéreo» son establecidas "con el alma, por ejemplo, o mejor, con su supuesto color» (1990: 437).

De nuevo ofrece Herrera valiosos y significativos ejemplos al respecto. En la ya aludida canción cuarta del segundo libro de los Versos, hay una detenida descripción de la blancura de la piel de la dama:

No è visto yo de púrpura encendida desvanecer la gracia a nueva rosa 
que solo se descubra su blancura,

qu'assí quede tan pura,

tan bella, tierna i de color perdida,

cuanto mi Luz turbada y lastimosa;

blanco alabastro el rostro parecía

blando i descolorido,

de pasión i de lástima ofendido,

que me robó el sossiego i alegría (vv. 65-74).

El poeta recurre a una comparación un tanto alambicada para culminar en el elogio de la piel de su dama, blanca como el alabastro. Herrera parte de que las rosas blancas, para adquirir tal color, pierden su matiz de "púrpura encendida», reducidas así a un níveo resplandor. Siendo así, en la naturaleza, por mucho que cualquier rosa pierda su color purpúreo, nunca conseguirá llegar a un color tan blanco, tan luminoso, con tonalidad «tan pura» como la de su dama cuando esta, «mi Luz», se siente "turbada y lastimosa». En el soneto XXviI de Algunas obras, cuando la dama enrojece nos muestra que «El color bello en el umor de Tiro/ardió, i con la nieve vuestra en llama pura».

Es interesante anotar que, en muchas ocasiones, la blancura de la piel resalta junto al dorado de los cabellos. Es el caso del ya citado soneto Ix, donde el hermoso cabello rubio de la dama "gentil corona en blanca frente ordena", o del LXVII del segundo libro de los Versos (2006: 707-708), en cuyo primer cuarteto leemos:

En sortijas i flores d'oro ardiente,

de perlas y rubíes coronada,

con hermosas figuras enlazada,

cercó mi Luz la bella i blanca frente.

La piel es blanca y luminosa en las damas renacentistas porque a través de ellas, según la lógica neoplatónica, se expresa la belleza de sus almas con plena potencia. Tal blancura se entiende del mismo modo en que la doctrina neoplatónica del Renacimiento concebía los cuerpos claros, diáfanos, transparentes. No hay que olvidar que un tratadista como León Hebreo explicaba que la luz no es «cualidad o pasión" de los cuerpos transparentes, sino «acto espiritual que actúa sobre lo diáfano por representación del iluminante y que se separa de él al quitar el iluminante», de modo que «la luz penetra por todo lo diáfano [...] sin límite ni medida» (2002: 177-178). El cuerpo de la dama petrarquista sería así como uno de estos cuerpos diáfanos, atravesado por la luz de su alma. De ahí que nos encontremos pieles que "adelgazando el blanco hasta la transparencia» (Larra Garrido 1997: 144) se conviertan en cristal. Lo comprobamos en Francisco de Aldana, cuando en la «Epístola a una dama» (1997: 131-136), junto al cabello dorado y a la piel blanca de rostro, haga del cuello puro cristal:

entre el claro marfil muy liso y puro, todo le debe ser claro y tratado; 
a cuello de cristal, coluna y muro

de todo bien, a mano tan hermosa,

sería lo más incierto más seguro (vv. 124-138).

Se trata una imagen de raíz neoplatónica en la que «la Idea de belleza al reflejar sobre el bulto material y vivo le presta su luz y abrillanta la alba superficie favoreciendo la tendencia a la cristalinidad» (Cossío 1926: 113).

El cuello de marfil, la mano blanca, el rostro entre rosa y azucena serán así elementos de atracción del amante, no por el color en sí, sino por la capacidad que tienen de expresar mejor que otras partes del cuerpo, o mejor que otras personas a las que el poeta no ame, la belleza luminosa del alma de la dama, chispa que, como sabemos, sustenta el fenómeno amoroso neoplatónico.

\subsection{Los ojos}

Resta por estudiar lo referente a los «claros ojos» de la dama, también dotados de naturaleza luminosa, pues se trata de un «mirar» que «con clara luz la tempestad serena». La imagen conoce en Herrera una amplia variedad de ejemplos. En una elegía incluida en los poemas en metro italiano (2006: 265-266), leemos que «Tan alta magestad, tanta grandeza / mostráis con vuestra luz, mis dulces ojos» (vv. 1-2); y en unas «Estançias» del libro primero de los Versos ruega a su dama que vuelva "con luz serena i regalada/los ojos que me tornan l'alegría» (vv. 171-172). Del mismo modo, Aldana, en su soneto XIX (1997: 203), hará jurar a Galatea «si más que estos dos ojos no te quiero, / que pierda yo la luz que en ellos tengo».

Conviene reparar, en primer lugar, en el hecho de que para el neoplatonismo renacentista la vista es de los cinco sentidos el más importante. Así lo atestigua León Hebreo (2002: 179), que afirma que «el órgano de la visión, tú misma lo ves, sobrepuja al de los demás sentidos en claridad, espiritualidad y artificio", amparándose en las razones que le da la autoridad aristotélica: «Por ello dice Aristóteles que amamos más el sentido de la vista que los otros, porque aquel nos proporciona más conocimiento que todos los demás», "como si el ojo fuese un espía del entendimiento y de todas las cosas inteligibles».

Tal capacidad se debe a su particular relación con el alma. Así lo expresa Marsilio Ficino en varios pasajes del De amore, en que describe los ojos como «puertas del espíritu», a través de las cuales «llegan muchas cosas al espíritu, y los afectos y las costumbres del espíritu se manifiestan muy claramente por los ojos» (1986: 149), de modo que estos son para el florentino "ventanas muy transparentes del espíritu» (p. 152). El hecho de que los ojos sean ventanas al alma conlleva una consecuencia que ya no debería sorprendernos: la hermosura del alma se expresa 
a través de los ojos. Lo comprobamos en el De amore a cuentas del circuito amoroso de los spiritus ${ }^{21}$ :

Y a través de aquéllos difunde las chispas de luz de los rayos a cada miembro, sobre todo a través de los ojos. Porque al ser el espíritu (spiritus) ligerísimo, fácilmente asciende a las partes más elevadas del cuerpo, y su luz resplandece más copiosamente por los ojos, porque los ojos son transparentes y, entre todas las partes del cuerpo, los más nítidos (p. 202).

Hebreo:

A ello contribuye la misma fisiología del órgano, tal como explica León

por estar compuesto de siete humores o capas, composición que es más admirable que la de cualquier otro miembro u órgano [...] los ojos no se asemejan a las demás partes del cuerpo; no son carnales, sino brillantes, diáfanos, espirituales, parecen estrellas, y exceden en belleza a todas las demás partes del cuerpo (2002: 179).

No es de extrañar, por tanto, que la caracterización de la dama petrarquista abunde en la representación luminosa, más si tenemos en cuenta que «el amor que tiene su principio en la luz que emanan los ojos de la amada constituye quizá la formulación más característica del estilo cortesano y neoplatónico" (Ruestes 1986: 86), pues no en vano Fernando de Herrera hablaba de «la viveza fogosa y aguda luz de los ojos» (2001: 335), de cómo "al principio nace el amor de un rayo de los ojos» (p. 324); de los ojos como "del alma luzes y del cielo estrellas», según explica en la canción en metro italiano a la que hicimos referencia más arriba (v. 44).

Si su cuerpo era dorado o cristalino debido a la expresión de la belleza del alma, no podrá ser menos aquella parte del mismo que más relacionada está con dicha expresión, que anatómicamente mejor permitirá la expresión de dicha luz. Como bien ha explicado Canone, en el neoplatonismo «lo stesso funcionamiento fisiologico dell'organo sensorio viene trasposto su un piano epifanico» (1996: 190), lógicamente relacionado con la fenomenología amorosa, ya que, en palabras de Margolin (1986: 596), hay una relación entre «la lumière et le regard, d'autre part, car sans la première le sens de la vue n'aurait aucun moyen de s'exercer. Mais aussi, et réunissant le tout, cette vision active et dirigée que l'on nomme regard et qui, captant la beauté, suscite l'amour».

Desde ese punto de vista entendemos que los ojos de la dama, su mirada, no pueden sino cifrarse en términos luminosos. De nuevo, no porque lo marque el tópico en un lugar de paso por el que debieran transitar los petrarquistas, sino porque la lógica del neoplatonismo no puede concebirlos de otra manera según su concepción del alma y del fenómeno amoroso. Basten algunos ejemplos para ilustrarlo, aparte de los ya señalados. Sin salir de Garcilaso, en la canción Iv, el poeta canta

${ }^{21}$ Cfr. Klein (1982: 29-59), Serés (1996: 54-136), Agamben (2006: 159-189). 
«Los ojos, cuya lumbre pudiera/tornar clara la noche tenebrosa/y escurecer el Sol a mediodía» (vv. 61-63).

Una vez más, Herrera nos ofrece ejemplos de la intensificación luminosa al respecto. Lo encontramos en los cuartetos del soneto IV del tercer libro de los Ver$\operatorname{sos}(2006: 755)$ :

Ojos, en quien mi espíritu respira

tal vez, ardiendo en lúcidas centellas;

ojos no, mas puríssimas estrellas;

rayos qu'el Sol menor celoso mira.

Rico puesto a do solo Amor espira, dichoso, en las eternas luzes bellas, i sus llamas afina, i tiempla en ellas, siempre fiero i cruel, l'aguda vira.

Tanta es la luz que desprenden los ojos de la dama en el soneto que son equiparados a las estrellas, hasta el punto de ser mirados con celo por parte del «Sol menor", que es el astro, en virtud de la comparación de su luz con la de la dama. El alma del poeta «respira» en unos ojos, los de la dama, en los cuales arden «lúcidas centellas», donde el amor «afina» y templa sus llamas, su «vira». Parecida comparación astronómica encontramos en el soneto Xciv del primer libro de los Versos, donde el Sol, Cupido y las estrellas encuentran su venero de luz y fuego:

Luzes, en quien su luz el Sol renueva,

i Cupido su llama, i las estrellas, con cuya claridad florecen bellas con el noturno orror, con l'alba nueva.

La misma idea encontramos en el segundo cuarteto del ya citado soneto xxxiII de Herrera, donde se dirige a las «Luzes, qu’al estrellado i alto coro/prestáis el bello resplandor sagrado».

En otras ocasiones, en fin, la luz de los ojos de la dama se suma a la del resto de elementos que conforman su imagen, en sinfonía luminosa entre todos ellos. Es el caso de un soneto del mismo Herrera (2006: 311):

Rosas de nieve y púrpura vestidas, coral roxo en marfil resplandeciente, estrellas que ilustráys la pura frente, en oro fino hebras esparzidas.

También lo es, en fin, el del soneto xvir del libro i de los Versos (2006: 513), en cuyos cuartetos volvemos a encontrar una imagen luminosa de los ojos de la dama en consonancia con el resto del cuerpo de la dama:

Las hebras que cogía en lazos d'oro con arte vuestra blanca y tierna mano 
mirava, i el semblante altivo i llano,

i la florida luz qu'amando adoro.

Creía, en vos, d'el sacro, ecelso coro,

qu'el esplendor s'unía soberano,

porqu'en sombra, aunque bella, i trage umano

no vio tal bien el orbe i tal tesoro.

\section{CONCLUSIONES}

Como se ha tenido oportunidad de comprobar, la imagen de la dama petrarquista -cabello rubio, piel blanca, ojos luminosos- durante el siglo Xvi trasciende el lugar común de los tópicos literarios. Si bien los poetas no tenían por qué ser conscientes del profundo trasfondo neoplatónico que sostiene la posibilidad de su lectura en el Renacimiento, los rasgos definitorios de tal imagen se explican según la filosofía de la luz ficiniana. Las diferentes partes del cuerpo de la dama participan de manera plena de ese resplandor que, en la tratadística renacentista, es la belleza de su alma, anzuelo que con su fuerza magnética irresistible atrae al enamorado poeta. No se trata simplemente de un mero modelo que se copiara sin medida durante la época; se trata de la única imagen posible para una época que hizo de la luz el vínculo de su mundo, su símbolo privilegiado; lo que late, en suma, bajo esta tan apasionada como luminosa petición de Aldana a su dama en una octava de su poema vi:

Por ese oro sutil, nuevo y luciente,

que por mano de Amor se ordena y mueve,

por esa de marfil graciosa frente

donde tiene el abril perpetua nieve,

mi Sol, os pido, y por la llama ardiente

que en mí la luz de vuestros ojos llueve,

que abráis a rato más gracioso y tierno

el alma, y gozarán las del infierno (vv. 169-176).

Recibido: abril de 2019; ACEPTAdo: mayo de 2019. 


\section{REFERENCIAS BIBLIOGRÁFICAS}

Agamben, Giorgio (2006): Estancias: la palabra y el fantasma en la cultura occidental, Valencia: Pretextos.

Aldana, Francisco de (1997): Poesías castellanas completas (ed. de José Lara Garrido) (2. ${ }^{a}$ ed.), Madrid: Cátedra.

Arce, Margot (1969): Garcilaso de la Vega: contribución al estudio de la lírica española del siglo XVI (3. ${ }^{a}$ ed.), San Juan de Puerto Rico: Universidad de Puerto Rico.

Bachelard, Gaston (1974): La formación del espiritu cientifico (3. ${ }^{a}$ ed.), Buenos Aires: Siglo XXI.

Blecua, José Manuel (ed.) (1955): Garcilaso de la Vega, Poesía. (4. ${ }^{a}$ ed.), Zaragoza: Ebro.

Canone, Eugenio (1996): «Il 'senso' nei trattati d'amore. Ficino e la fortuna del modello platonico nel Cinquecento", en M.L. Bianchi (ed.), Sensus, sensatio: 8. Colloquio internazionale, Roma, 6-8 gennaio 1995, Firenze: L.S. Olschki, 177-198.

Castelli, Patrizia (1984): "Orphica», en P. Castelli (ed.), Il lume del sole: Marsilio Ficino medico dell'anima: Figline Valdarno, Vecchio Palazzo Comunale, 18 maggio-19 agosto 1984, Firenze: Opus Libri, pp. 51-64.

Castiglione, Baltasar (2009): El cortesano (ed. de Rogelio Reyes Cano), Madrid: Espasa-Calpe.

Chastel, André (1982): Arte y humanismo en Florencia en la época de Lorenzo el Magnífico, Madrid: Cátedra.

Chastel, André (1996): Marsile Ficin et l’art, Genève: Droz.

Cossío, José María de (1926): «Candores, esplendores», Revista de Occidente, 40: 110-113.

Coster, Adolphe (1908): Fernando de Herrera: (El Divino): 1534-1597, Paris: Honoré Champion.

Culianu, Ioan P. (1999): Eros y magia en el Renacimiento, 1484, Madrid: Siruela.

Dagron, Tristan (ed.) (2006): León Hebreo, Dialogues d'amour, Paris: Librairie philosophique J. Vrin.

De la Villa, Rocío (ed.) (1986): Marsilio Ficino, De amore. Comentario a "El Banquete» de Platón, Madrid: Tecnos.

Díaz-Urmeneta, Juan Bosco (2004): La tercera dimensión del espejo: ensayo sobre la mirada renacentista, Sevilla: Universidad de Sevilla.

Dronke, Peter (1978): La lírica en la Edad Media, Barcelona: Seix Barral.

Eco, Umberto (2004): Historia de la belleza, Barcelona: Lumen.

Ferraté, Joan (1982): Dinámica de la poesía: ensayos de explicación, 1952-1966 (2. a ed.), Barcelona: Seix Barral.

Festugière, André-Jean (1941): La philosophie de l'amour de Marsile Ficin et son influence sur la littérature française au XVIe siècle, Paris: Libraire Philosophique J. Vrin.

Ficino, Marsilio (1986): De Amore. Comentario a «El Banquete» de Platón (ed. de Rocío de la Villa Ardura), Madrid: Tecnos.

Ficino, Marsilio (2001): Platonic theology (ed. de M.J.B. Allen) (vol. 1), Cambridge (Mass.): Harvard University Press.

Ficino, Marsilio (2002): Platonic theology (ed. de M.J.B. Allen) (vol. 2), Cambridge (Mass.): Harvard University Press. 
Ficino, Marsilio (2003): Platonic theology (ed. de M.J.B. Allen) (vol. 3), Cambridge (Mass.): Harvard University Press.

Ficino, Marsilio (2013): Sobre el Sol. Sobre el lumen (Liber de sole et lumine) (ed. de A. Flórez Jiménez), México D.F.: Bonilla Artigas Editores [Edición electrónica].

García de la Concha, Víctor (1986): «La oficina poética de Garcilaso», en Víctor García de la Concha (ed.), Garcilaso: actas de la IV Academia Literaria Renacentista, Universidad de Salamanca, 2-4 de marzo de 1983, Salamanca: Universidad de Salamanca, Servicio de Archivos y Bibliotecas: 83-106.

Garcilaso de la Vega (2007): Obra poética y textos en prosa (ed. de Bienvenido Morros), Barcelona: Crítica.

GARIN, Eugenio (2000): Medioevo y renacimiento: estudios e investigaciones, Madrid: Taurus.

Garrote Pérez, Francisco (1997): «La belleza del retrato en Herrera», Insula: revista de letras y ciencias humanas 610: 21-23.

Herrera, Fernando de (2001): Anotaciones a la poesía de Garcilaso (ed. de José María Reyes e Inoria Pepe), Madrid: Cátedra.

KLEIN, Robert (1982): La forma y lo inteligible: escritos sobre el Renacimiento y el arte moderno, Madrid: Taurus.

LAPEsa, Rafael (1985): La trayectoria poética de Garcilaso, Madrid: Istmo.

Lara Garrido, José (1997): Del Siglo de Oro: métodos y relecciones, Madrid: CEES.

LeÓn, Luis de (1987): La perfecta casada (ed. de Mercedes Etreros), Madrid: Taurus.

León Hebreo (2002): Diálogos de Amor (ed. de Andrés Soria Olmedo), Madrid: Tecnos.

Lida de Malkiel, María Rosa (1975): La tradición clásica en España, Barcelona: Ariel.

MACrí, Oreste (1972): Fernando de Herrera (2. ${ }^{a}$ ed. corregida y aumentada), Madrid: Gredos.

Manero Sorolla, María del Pilar (1990): Imágenes petrarquistas en la lírica española del Renacimiento: repertorio, Barcelona: PPU.

Manero Sorolla, María del Pilar (1992): «La configuración imaginística de la dama en la lírica española del Renacimiento: la tradición petrarquista», Boletín de la Biblioteca de Menéndez Pelayo 68: 5-71.

Manero Sorolla, María del Pilar (2005): «Los cánones del retrato femenino en el "Canzoniere": difusión y recreación en la lírica española del Renacimiento", Cuadernos de filología italiana 12: 247-260.

Margolin, Jean-Claude (1986): «Du “De amore” à la “Delie” de Scève», en G.C. Garfagnini (ed.), Marsilio Ficino e il ritorno di Platone: studi e documenti, Firenze: L.S. Olschki, 587-614.

Matton, Sylvain (1981): «En marge du De lumine: splendeur et mélancolie chez Marsile Ficin», en Lumière et cosmos: courants occultes de la philosophie de la nature, Paris: Albin Michel, 31-54.

Menéndez Pelayo, Marcelino (1974); Historia de las ideas estéticas en España (Vol. I), Madrid: Consejo Superior de Investigaciones Científicas.

Morros, Bienvenido (ed.) (2007): Garcilaso de la Vega, Obra poética y textos en prosa, Barcelona: Crítica.

Muñız, María de las Nieves (2014): «La descriptio puellae: tradición y reescritura», en El texto infinito. Tradición y reescritura en la Edad Media y el Renacimento, Salamanca: SEMYR, 151-189. 
Muñız, María de las Nieves (2018): La descriptio puellae nel Rinascimento: percorsi del topos fra Italia e Spagna con un'appendice sul locus amoenus, Firenze: Cesati.

Navarro Durán, Rosa (ed.) (1994): Francisco de Aldana, Poesía, Barcelona: Planeta.

Navarro Durán, Rosa (1997): «El argumento de amor en los sonetos de "Algunas obras"», Insula: revista de letras y ciencias humanas 610: 4-6.

PAnofsky, Erwin (2008): Estudios sobre iconología, Madrid: Alianza Editorial.

PARKer, Alexander (1986): La filosofía del amor en la literatura española: 1480-1680, Madrid: Cátedra.

Pico della Mirandola (2000): «Discurso de la dignidad del hombre», en María Morrás (ed.), Manifiestos del humanismo: Petrarca, Bruni, Pico della Mirandola, Alberti, Barcelona: Península, 97-133.

PozzI, Giovanni (1976): «Codici, stereotipi, topoi e fonti letterarie», en Intorno al Codice: Atti del III Convegno della Associazione Italiana di Studi Semiotici (AISS): Pavia 26-27 settembre 1975, Firenze: La Nuova Italia, 37-76.

Pozzi, Giovanni (1979): «Il ritratto della donna nella poesia d'inizio Cinquecento e la pittura di Giorgione», Lettere italiane xxxI (1): 309-341.

Quondam, Amedeo (1991): Il naso di Laura: lingua e poesia lirica nella tradizione del clasicismo, Modena: F.C. Panini.

Raimond, Ezio (1982): Metafora e istoria. Studi su Dante e Petrarca, Torino: Einaudi.

Reichenberger, Arnold G. (1962): "Competitive Imagery in Spanish Poetry», Annali dell'Istituto Universitario Orientale. Sezione Romanza IV (1): 83-97.

Rivers, Elías L. (ed.) (1957): Garcilaso de la Vega, Poesías, Madrid: Espasa-Calpe.

Reyes Cano, Rogelio (ed.) (2009): Baltasar Castiglione, El Cortesano, Madrid: Espasa-Calpe.

Rodríguez, Juan Carlos (1990): Teoría e historia de la producción ideológica: las primeras literaturas burguesas (2. ${ }^{\mathrm{a}} \mathrm{ed}$.), Madrid: Akal.

Ruestes, María Teresa (ed.) (1986): Fernando de Herrera, Poesía, Barcelona: Planeta.

Saitta, Giuseppe (1923): La filosofia di Marsilio Ficino, Messina: Principato.

SERÉs, Guillermo (1996): La transformación de los amantes: imágenes del amor de la antigüedad al Siglo de Oro, Barcelona: Crítica.

Soria Olmedo, Andrés (ed.) (2002): León Hebreo, Diálogos de amor, Madrid: Tecnos.

TRILlini, Matteo (2017): «La "Descriptio puellae” en el petrarquismo italiano y español: los ejemplos de Giusto de' Conti y Garcilaso de la Vega», Revista de filología románica 34(2): 267-280.

Vicente, Luis Miguel (2007): «La Venus Urania de Garcilaso frente a la Venus Pandemo de Aldana y de otros petrarquistas españoles", Edad de oro 26: 315-345.

WInd, Edgar (1998): Los misterios paganos del Renacimiento, Madrid: Alianza. 